\title{
PREVALENCE OF KLEBSIELLA PNEUMONIAE IN BROILER CHICKS
}

\author{
Eman, M.Elashmony; Fares, F. El-Khyat and El-Gohary; A.A.
}

Department of Poultry \& Rabbit diseases; Faculty of Vet. Medicine; Kafrelsheikh University.

\begin{abstract}
The aim of this study was to investigate the role of Klebsiella pneumoniae bacterial infection in causing mortalities in broiler chicks. Trials were carried out to isolate and identify Klebsiella Pneumoniae Spp from 1-7day-old broiler chicks suffering from mortalities during first week of age. Followed by Antimicrobial sensitivity test. Results of isolation and identification using biochemical tests followed by Duplex polymerase chain reaction technique confirmed that $21 \%$ of the broiler chicks flocks were positive to Klebsiella pneumoniae Spp. Mortalities ratio in the investigated flocks were (0.3\%-5\%) at the first week. Using Antibiotic sensitivity test, Thiamphenicol (Tersan $\circledR_{20 \%)}$ was found to be best effective drug to overcome the infection with Klebsiella pneumoniae Spp. in broiler chicks. Further studies are needed to delineate that presence of Klebsiella Pneumoniae Spp is linked to clinical disease and mortality in baby chicks.
\end{abstract}

\section{INTRODUCTION}

Klebsiella is a genus of non-motile, Gram-negative, oxidasenegative, rod-shaped bacteria with a prominant polysaccharide-based capsule, belong to the family Enterobacteriaceae (Ryan and Ray, 2004). 
Klebsiella species are classified as one of the opportunistic bacteria that normally inhabit the gastrointestinal tract of healthy humans and animals, and are also commonly found in the environment (Kim,et al., 2005).

Klebsiella species are found everywhere in nature. This is thought to be due to distinct sublineages developing specific niche adaptations, with associated biochemical adaptations which make them better suited to a particular environment. They can be found in water, soil, plants, insects, animals, and humans (Brisse, et al., 2006).

Klebsiella pneumoniae has been reported as one of the bacteria infecting the yolk sac and causing embryos and chicks mortalities during their first week of life (Orajaka and Mohan, 1985).

Klebsiella species are normal intestinal flora of poultry, but could cause infections whenever the immune system of affected bird is compromised (Younis, et al., 2016).

The improper hens farm management techniques and or improper hygiene may facilitate contamination of eggs with Klebsiella species (Podshchun et al., 2001).

It was found that the total enterobacterial count obtained from hatchery waste comprises empty shells, infertile eggs, dead embryos, ranged from $6.0 \times 104$ to $3.0 \times 105 \mathrm{cfu} / \mathrm{g}$ for hatchery waste and the bacteria isolated from hatchery waste were Staplylococcus epidermidis, Esherichia coli, Bacillus spp., Klebsiella pneumoniae and Pseudomonas aeruginosa (Onwenefah and Adedeji, 2013). 
Yolk sac infection is a major cause of mortality in broilers during their first week of life. It occurs in all flocks resulting in decreased hatchability, increased mortality and increased cull rate due to retarded growth. It occurs mainly due to bacterial contamination of the eggshell at the broiler breeder farm, shortly after the egg is laid, while the cuticle is still moistened. Contamination-promoting factors include lack of hygiene in the nests, presence of eggs on the floor, incubation of dirty eggs or eggs with eggshell defects, and collection of dirty and clean eggs at the same time. Alternatively, poor fertile egg storage conditions, poor egg disinfection, and high humidity levels during incubation may also promote yolk sac infection. Another important route of contamination of the yolk sac is the bacterial penetration through a poorly healed navel (Coutts, 1981 and Danka et al., 2012).

\section{MATERIAL AND METHODS}

\subsection{Broiler chicks:}

1-7 day -old chick in broiler chicken farms in El- Gharbia Province were examined for bacterial isolation of Klebsiella pneumoniae. (Table 1).

\subsection{Samples:}

A total of 100 samples in which 5 livers and 5 yolk sacs for each flock considered as a specimen were collected from 1-7 day old dead and diseased broiler chicks in 100 broiler chicken farms in El- Gharbia Province, (Table 1). 
Table (1): Samples collected from broiler chicken farms for trials of isolation of Klebsiella pneumoniae spp.

\begin{tabular}{|c||c||c||c||c|}
\hline No. of Flocks & Flock Size & Age at collection & $\begin{array}{c}\text { Specimens (livers } \\
\text { and yolk sacs) }\end{array}$ & $\begin{array}{c}\text { Mortality ratio at } \\
\text { first week }\end{array}$ \\
\hline \hline 100 & 250000 & $1-7$-days- old & 100 & $0.3 \%-5 \%$ \\
\hline
\end{tabular}

These samples were collected aseptically, placed in sterile plastic bags for transportation, and kept in refrigeration .Samples were cultivated on nutrient broth and incubated aerobically at $37{ }^{\circ} \mathrm{C}$ for $18-24$ hrs. (A loopful of inoculated nutrient broth was streaked on to MacConkey's agar. (Dashe et al., 2013).

\subsection{Media used for isolation of Klebsiella Pneumoniae:}

Nutrient broth medium (Oxoid) and MacConkey's bile salt agar media (Oxoid)and X.L.D.agar(Oxoid).

\subsection{Media used for biochemical reactions:}

peptone water broth (Oxoid), Glucose phosphate broth (Oxoid), Simmon's citrate agar medium (Oxoid), Triple sugar iron agar medium (TSI) (Oxoid), Christensen's urea agar base (Oxoid), according to (Cruickshank et al., 1975).

\subsection{Molecular detection of $K$. pneumoniae:}

The Molecular detection of K. pneumoniae 16S-23S ITS gene using duplex polymerase chain reaction (PCR) with using of primer ATT TGA AGA GGT TGC AAA CGA T and TTC ACT CTG AAG TTT TCT TGT GTT C, according to (Turton et al., 2010). 


\section{6- Sensitivity test of Klebsiella Pneumonae for antibacterial drugs according to Finegold and Martin (1982):}

Mueller Hinton broth and Mueller Hinton agar used for sensitivity test in which produce clear zone of bacterial growth inhibition which differ in diameter according to degree of sensitivity. Antimicrobial discs (Oxoid) containing different concentrations the following antimicrobial disks were used:

Amoxicillin/Clavulinic acid (AMC, 30 $\mu$ ), Cefoperazone (CFP,

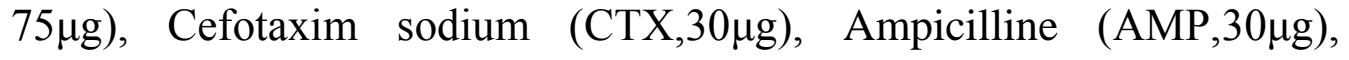

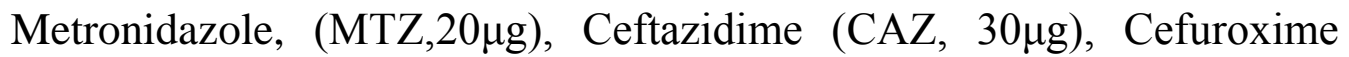

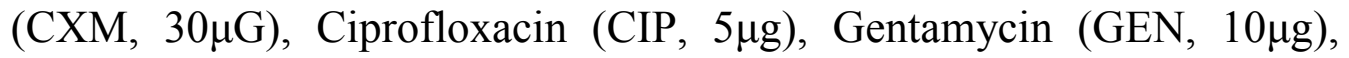

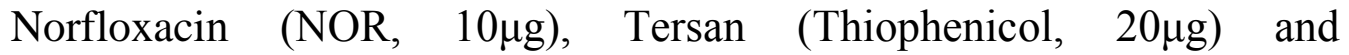
Trimethoprim/sulphamethoxazole (SXT, 25 $\mu \mathrm{g}$ ).

\subsection{Experimental infection in broilers against Klebsiella Pneumonae:}

A total of 210 day-old chicks obtained from Waddi company were allotted in to four groups of 50 chicks for each (Table3).

Table(3): The dealing program with the broiler groups.

\begin{tabular}{|c||c||}
\hline \hline Groups (G) & Treatment \\
\hline \hline \multirow{2}{*}{ G1 } & $\begin{array}{c}\text { Infected with Klebsiella Pneumonae at } 20^{\text {th }} \text { day of age then treated with } \\
\text { Thiomphenicol, 20\% }\end{array}$ \\
\hline \multirow{2}{*}{ G2 } & $\begin{array}{c}\text { Infected with Klebsiella Pneumonae at } 20^{\text {th }} \text { day of age then treated with } \\
\text { SXT, 25\% }\end{array}$ \\
\hline \multirow{2}{*}{ G3 } & $\begin{array}{c}\text { Infected with Klebsiella Pneumonae at } 20^{\text {th }} \text { day of age but not treated } \\
\text { (positive control) }\end{array}$ \\
\hline G4 & Not infected not treated (negative control) \\
\cline { 2 - 2 } &
\end{tabular}


Before starting experiment 10 chicks were euthanized and samples were taken from heart,liver and yolk sac and cultured as shown in 2.3 to make sure that chicks are free fom Klebsiella Pneamoniae.

Birds in all groups were vaccinated at 7 th day-old with (Clone+I.BMA5) eye drop method,then vaccinated at 14th day old by Gumboro disease vaccine (Univax) eye drop method ,followed by Newcastle disease vaccinND6/10 eye drop method at 18th day of age.

chicks were fed adlibitum Birds were challenged with $0.5 \mathrm{ml}$ injection that approximately containe $5 \times 109$ m.o/ml (Gradwhole1956) then observed.

Samples were taken from liver,heart,intestine and lung for isolation of Klebsiella Pneamoniae .samples are taken for P/M examination.

Samples also taken from lung,liver,heart and intestine for histopathological examination. Morbidities and mortalities are recorded.

\section{RESULT AND DISCUSSION}

The results revealed that 21 out of 100 examined broiler flocks at first week of age were positive for isolation of Klebsiella pneumoniae. So, it could be concluded that Klebsiella pneumoniae act as one of causes of about $21 \%$ of the disease and mortalities at the first week of age in broiler chicks which concided with (Coutts, 1981 , and Danka et al., 2012) as reported that yolk sac infection is a major cause of mortality in broilers during their first week of life. It occurs in all flocks resulting in decreased hatchability, increased mortality and increased cull rate due to retarded growth. It occurs mainly due to bacterial contamination of the egg shell at the broiler breeder farm. 


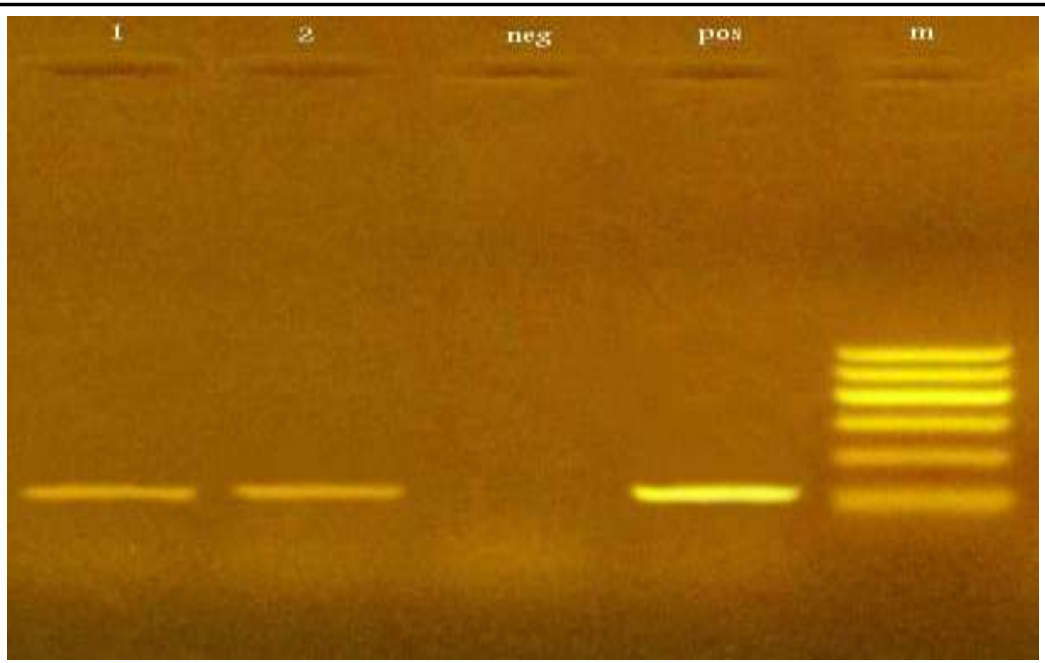

Fig. (1): Agarose gel electrophoresis showing duplex PCR amplification at 130 bp and 343bp for 16S-23S ITS gene of K. pneumoniae.

Lane (m): 100 bp molecular size marker, lane (pos.): positive control K. pneumoniae ATCC®13883 and lane (neg.): negative control E. coli ATCC@8739.

Lanes $(1,2)$ positive samples for the presence of $16 \mathrm{~S}-23 \mathrm{~S}$ ITS gene of $K$. pneumoniae (130 bp).

The result of biochemical tests demonstrated that the isolated bacterial spp. gave positive reaction for catalase test, Voges-Proskaure test, urease and citrate test. While it was negative for oxidase, methyl red, and indole test which could detected that this bacterial isolate was Klebsiella pneumoniae as it was reported by (Aher et al., 2012).

Two random isolates were selected out of 21 isolates of Klebsiella pneumoniae according to the results of selective biochemical tests for molecular detection using duplex PCR which detected 2 positive samples for the presence of 16S-23S ITS gene of K. pneumoniae fig (1). 
Klebsiella strains recorded high antibiotic resistance with multiple antibiotic resistance which may be due to the hazard routinely uses of antibiotics for treatment and control of bacterial diseases in human and poultry farms. In addition, releasing of beta-lactamases which are the commonest single cause of bacterial resistance to beta-lactam antibiotics as Klebsiella pneumoniae represent one of the most prevalent species could expressed an extended spectrum beta lactamase as reported by (Livermore, 1995; Galas et al., 2008, and Kilonzo et al., 2008).

In this study, there are 21 Klebsiella pneumoniae isolates were tested against 17antimicrobial agents using Kirby - Bauer disk diffusion assay in which the result of antibiotic sensitivity test indicated that the sensitivity of isolated Klebsiella to different antibiotics. They were sensitive to Thiamphenicol (100\%) followed by Trimethoprim/ sulphamethoxazole (SXT, 25 $\mathrm{g}$ ). Ciprofloxacin and Gentamycin (75\%), (Table 2).

Table (2): Results of sensitivity of Klebsiella pneumoniae to antimicrobial drugs.

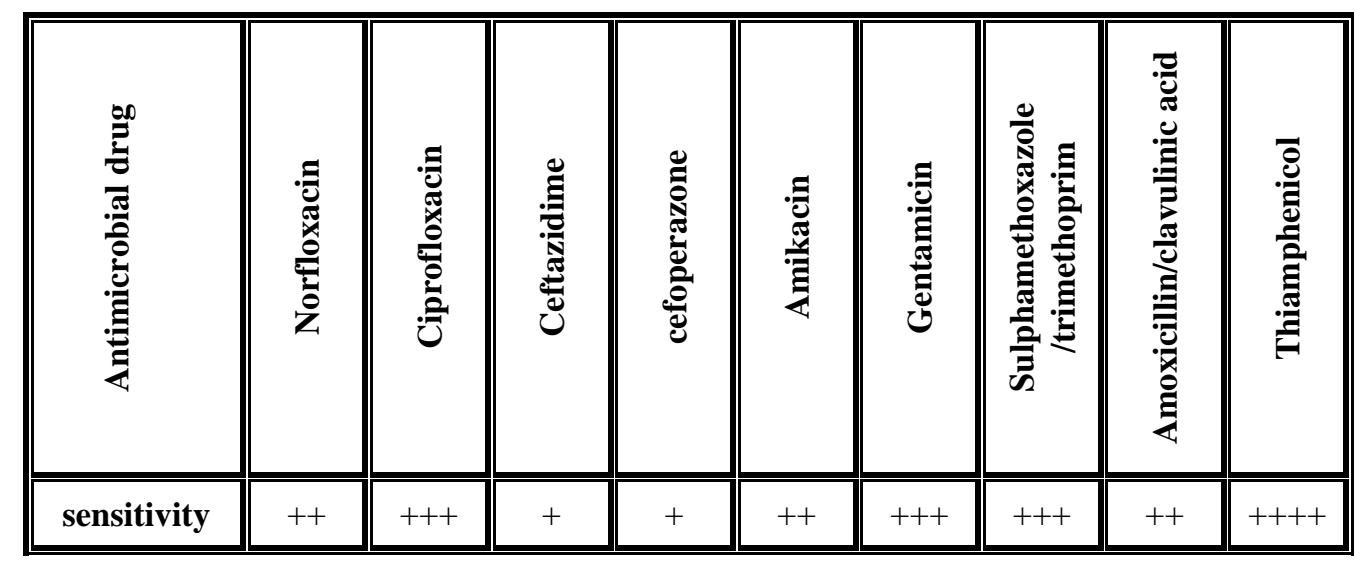

$\overline{\overline{\text { Kafrelsheikh Vet. Med. J. Vol. } 16 \text { No. } 1 \text { (2018) }}}$ 


\section{CONCLUSION}

Klebsiella pneumoniae Spp. act as one of the bacteria commonly isolated from baby chicks suffering from yolk sac infection and variable mortalities .

Klebsiella pneumoniae Spp may contribute in the occurrence of these early problems in baby chicks in the first week of age. The antibiotic sensitivity test indicated that Thiamphenicole $20 \%$ was the best effective drug to overcome the infection with Klebsiella pneumoniae Spp. in broiler chicks.

\section{REFERENCES}

- Aher, T.; Roy, A. and Kumar, P. (2012): Molecular detection of virulence genes associated with pathogenicity of Klebsiella spp. isolated from the respiratory tract of apparently healthy as well as sick goats. Israel Journal of Veterinary Medicine, 67(4), 249-252.

- Brisse, S.; Grimont, F.; and Grimont, P. A. (2006): The genus Klebsiella. In the prokaryotes (pp. 159-196). Springer New York.

- Coutts G.S. (1981): Poultry diseases under modern management $2^{\text {nd }}$ edition. Saiga Publishing Co. LTD. pp. 36-41. London. England.

- Cruickshank, R., Duguid, J. P., Marmion, B. P., and Swain, R. H. A. (1975): Medical Microbiology, Volume II, 12th edition. Churchill Livingstone, Edinburgh, London and New York.

- Danka Maslic-Strizak, Ljiljana Spalevic and Radmila Resanovic, (2012): The Influence of Klebsiella Bacterial Infection on Results of Hatchery and Quality of one day old Broiler chickens., https://en. engormix.com/poultry-industry/articles/klebsiella-bacterial-infectiont35274.htm. 
- Dashe, Y. G.; Raji, M. A.; Abdu, P. A.; Oladele, B. S.(2013): Distribution of aerobic bacteria in visceral organs of sick and apparently health chicken in Jos, Nigeria .International Research Journal of Microbiology (IRJM) (ISSN:2141-5463) Vol . 4(3) pp. 7983, March 2013.

- Finegold, S. M. and Martin, W. J. (1982): Diagnostic Microbiology $7^{\text {th }}$. Mosby. London.

- Galas, M.; Decousser, J.W.; Breton, N.; Godard, T.; Allouch, P.Y. and Pina, P., college de Bacteriologic Nirologic Itygiene (COLBHV) study Group (2008): Nationwide study of the prevalence, characteristic and molecular epidemiology of extended spectrum betalactamase producing Enterobacteriacea in France .Antimicrob agent's Chemother.52 (2):786-789.

- Kim, S. H.; Wei, C. I.; Tzou, Y. M. and An, H. (2005): Multidrugresistant Klebsiella pneumoniae isolated from farm environments and retail products in Oklahoma. Journal of Food Protection, 68(10), 2022-2029.

- Kilonzo-Nthenge, A.; Nahashon, S. N.; Chen, F. and Adefope, N. (2008): Prevalence and antimicrobial resistance of pathogenic bacteria in chicken and guinea fowl. Poultry science, 87(9), 1841-1848.

- Livermore, D. M. (1995): Beta-Lactamases in laboratory and clinical resistance. Clinical microbiology reviews, 8(4), 557-584.

- Onwenefah, M. and Adedeji, O. B. (2013): Bacterial flora of cultured catfish fed with poultry hatchery waste from selected farms in Ibadan Southwestern Nigeria. 
- Orajaka, L.J. and Mohan, K. (1985): Aerobic bacterial flora from dead-in-shell chicken embryos from Nigeria, Avian Dis., 29: 583-9.

- Podschun,R.; Pietsch, S.; Holler, C. and Ullmann (2001): Incidence of Klebsiella species in surface waters and their expression of virulence factors. Applied and environmental microbiology, 67(7), 3325-3327.

- Ryan KJ and Ray CG (2004): Sherris Medical Microbiology (4th ed.). McGraw Hill. p. 370. ISBN 0-8385-8529-9. 2.

- Turton, J. F.; Perry, C.; Elgohari, S. and Hampton, C. V. (2010): PCR characterization and typing of Klebsiella pneumoniae using capsular type-specific, variable number tandem repeat and virulence gene targets. Journal of medical microbiology, 59(5), 541-547.

- Younis, G.; Awad, A.; El-Gamal, A. and Hosni, R. (2016): Virulence properties and antimicrobial susceptibility profiles of Klebsiella species recovered from clinically diseased broiler chicken. Adv. Anim. Vet. Sci. 4(10): 536-542. 